\title{
molecules
}

ISSN 1420-3049

www.mdpi.com/journal/molecules

Review

\section{Applications of Biomaterials to Liquid Crystals}

\section{Kazuki Iwabata ${ }^{1{ }^{*}, \text { Urara Sugai }}{ }^{1}$, Yasutaka Seki ${ }^{1}$, Hirokazu Furue ${ }^{2}$ and Kengo Sakaguchi ${ }^{1}$}

1 Department of Applied Biological Science, Tokyo University of Science, 2641 Yamazaki, Noda, Chiba 278-8510, Japan; E-Mails: sugai.urara.63@gmail.com (U.S.); y.seki1030@gmail.com (Y.S.); kengo@rs.noda.tus.ac.jp (K.S.)

2 Department of Industrial Chemistry, Tokyo University of Science, 2641 Yamazaki, Noda, Chiba 278-8510, Japan; E-Mail: hfurue@rs.noda.tus.ac.jp

* Author to whom correspondence should be addressed; E-Mail: iwabata@rs.noda.tus.ac.jp; Tel.: +81-4-7124-1501 (ex. 3437); Fax: +81-4-7123-9767.

Received: 17 January 2013; in revised form: 10 April 2013 / Accepted: 17 April 2013 /

Published: 19 April 2013

\begin{abstract}
Nowadays, chemically synthesized proteins and peptides are attractive building blocks and have potential in many important applications as biomaterials. In this review, applications of biomaterials to thermotropic liquid crystals are discussed. The review covers the improvement of the performance of liquid crystal displays using liquid crystal physical gels consisting of a liquid crystal and amino acid-based gelators, and also new functionalization of liquid crystals. Moreover, the influence of DNA, which is one of the more attractive biomaterials, dispersed in thermotropic liquid crystals and its potential use in the liquid crystal industry is described. In addition, we found interesting results during electrooptical measurements of liquid crystals doped with DNA, and explain them from the point of view of biological applications. These recent approaches suggest that these biomaterials may be applicable in the electronic device industry and should be considered as an interesting material with their physical properties having the potential to create or refine an industrial product.
\end{abstract}

Keywords: liquid crystal; biomaterial; DNA; peptide 


\section{Introduction}

In recent years chemically synthetized peptides and proteins have attracted the attention of researchers working in various areas of science. One of the more interesting of these new research areas is the exploitation of peptides for the assembly of nanomaterials [1]. Peptides are particularly attractive as molecular building blocks in the bottom-up fabrication of supramolecular structures based on self-assembly and have potential in many important applications. Cavalli et al. demonstrated the importance of amphiphilic peptides as molecular building blocks for nanostructures through discussion of several examples of applied nanomaterials [2]. There are also many reports which describe applications of peptide-based self-assembled structures [3-5]. Along with peptides, much attention has also been focused on the rational design of self-assembled nanostructures using biomaterials such as DNA, RNA, and polypeptides [6-14]. Furthermore, as examples of the research into physical and chemical properties of the materials, Lowik et al. give an introduction into the field of stimulus-responsive peptide-based materials [15]. They have tried to categorize them according to the stimulus the materials are responsive to, these being $\mathrm{pH}$, temperature, metal ions, enzymes and light.

The techniques and the knowledge produced by these developments have spread to other areas. One example is that there have been moves to apply biomaterials to electronic devices. Amyloid fibrils are one of several self-assembling peptide systems that are attracting increasing interest for molecular electronics applications $[12,16,17]$. Del Mercato et al. demonstrated that nanofibrils can sustain significant electrical conduction in the solid state at ambient conditions and have remarkable stability [17]. Recently, with the development of the technology of self-assembled nanostructures using biopolymers, biomaterials seem to be ideally suited to improve the performance of photovoltaic and organic field effect transistor devices [18]. By the attachment of an oligothiophene derivative to the side chain of L-lysine and subsequent polymerization to the corresponding poly-L-lysine derivative, the resulting compound provided an improved photovoltaic and organic field effect transistor device [18].

In this review, we give other examples of biomaterials applied to electronic devices, especially liquid crystals (LCs), and show their possibilities. Since the pocket calculator with LC display was first introduced in 1973, liquid crystals are now used in flat-panel televisions across the globe [19]. Even now, there are a lot of studies to open up the potential of liquid crystals. We describe some of these approaches in this review.

\section{What are Liquid Crystals?}

Liquid crystals may flow like a liquid, but the molecules in the liquid are arranged and/or oriented in a crystal-like manner. There are two generic classes of liquid crystals: those whose transitions are driven by thermal processes, known as thermotropic liquid crystals, and those strongly influenced by solvents, known as lyotropics. Many thermotropic LCs exhibit a variety of phases as the temperature is changed. For instance, a particular type of LC molecule may exhibit various smectic and nematic phases as the temperature is increased. Thermotropic liquid crystal materials have characteristics related to their molecular structure, which consist of two parts, namely the core and side chain. The core part is a rigid body which brings shape anisotropy to the molecule, and the side chain part is a flexible region which gives mobility. Figure 1 shows a typical thermotropic liquid crystal, 
4-cyano-4'-pentylbiphenyl (5CB). These liquid crystal materials are being constantly developed and improved, and used industrially in various ways such as in displays, film, drugs and medicines. Kato et al. and Gao et al. have recently reported that dendritic oligopeptides can act as useful building blocks for chiral supramolecular liquid crystals [20-22].

Figure 1. An illustration of the structure of $5 \mathrm{CB}$.

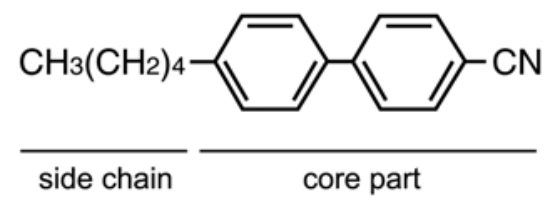

In contrast, lyotropic liquid-crystal materials may not necessarily possess shape anisotropy, but rather self-assemble depending on their concentration in a solvent. There is a connection between biomaterials and liquid crystals [23]. According to Robinson, pure DNA forms liquid-crystalline phases in vitro [24]. Also, it has been known that DNA exhibits: (i) precholesteric or blue phases, (ii) chiral nematic (also known as cholesteric), and (iii) columnar phases, on increasing concentration (Figure 2). This has been determined from ex vivo studies using aqueous solutions [23-28]. Furthermore, DNA forms a hexagonal columnar phase in association with cationic lipids, which is expected to be an alternative carrier for gene therapy without using a virus [29-31]. Powell et al. described how the formulation of Deterelix, a hydrophobic Luteinizing Hormone Releasing peptide, rapidly formed nematic peptide liquid crystals of undulose extinction when in aqueous solution [32]. While lyotropic LCs are very widely used in cosmetics and beauty care and have been explored for their potential applications, in this review, we focus on thermotropic liquid crystals because there are few reports describing the application of biomaterials to thermotropic LCs although thermotropic liquid crystals applied to LCDs have been well-researched and are already in commercial use [33].

Figure 2. The schematics of nucleic-acid based liquid crystal phases. Adapted with permission from [27].

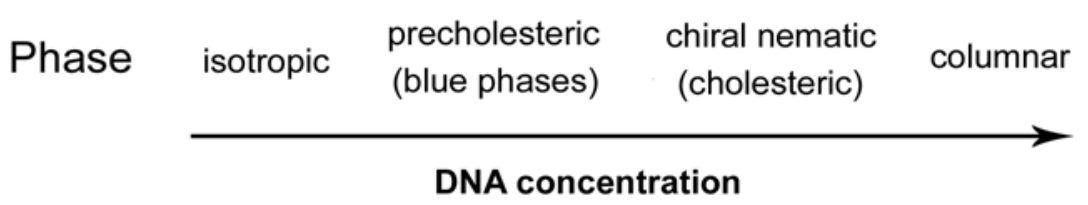

\section{New Functional LC Modulated with Peptide}

Recently, there have been new approaches to producing new functional LC materials which induce amino acids or peptides. In the traditional development process of liquid crystal molecules used for displays, there is no need to consider the introduction of functional groups which induce strong intermolecular interactions, such as hydrogen bonds, electrostatic interactions, and charge transfer interactions, but utilization of these functional groups cannot be ignored when it comes to the evolution and development of novel applications of liquid crystals.

Kato and collaborators have succeeded in the preparation of LC physical gels with new structures and functions [34-42]. LC physical gels are composites consisting of a liquid crystal and a small 
amount of self-assembled fibers [34]. The fibrous materials are simply formed in the liquid crystals by self-assembly of low-molecular-weight compounds (gelators) which have amino acid (or a derivative) moieties in their chemical structure, a process which is driven by hydrogen-bonding. The number of amino acid moieties in the gelators has a large effect on the gelation ability and the electro-optical behaviour of the resulting LC gels (compounds 1 and 2 in Figure 3) [35]. These materials are soft solids retaining liquid-crystalline properties (compounds 1-4 in Figure 3).

Figure 3. Chemical structures of gelators.
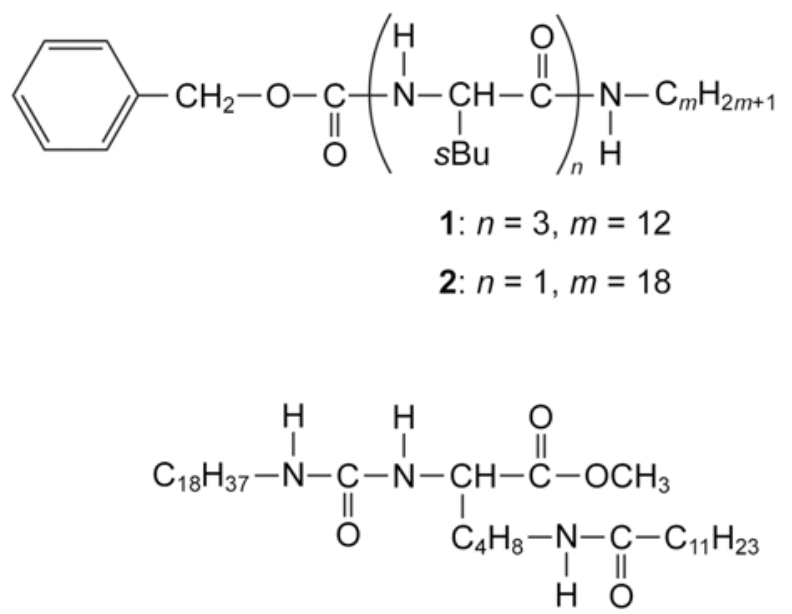

3<smiles>CC(C)C(NC(=O)OCc1ccccc1)C(=O)Nc1ccccc1</smiles>

4<smiles>CCCCCCOc1ccccc1</smiles>

5

Such gels show thermoreversible sol-gel transitions which arise from the association and dissociation of intermolecular interactions between the gelators [34]. For LC physical gels, the LC and gelators show individual transitions. By using the gelators, they have found that physical gelation of liquid crystals improved the response speeds of liquid crystals to electric fields [36,37]. They explained that the existence of the finely dispersed aggregates of the gelator induces LC alignment states that are both metastable and responsive. Moreover, the interactions between the liquid crystals and the fibrous aggregates properly weaken an alignment force to the LC molecules conveyed from the rubbed-polyimide surfaces, which leads to the faster response [36]. Another gelator which is a monodisperse homomeric dipeptide also improves the dynamic characteristics of the electro-optical switching of the device employing these gels (compound 5 in Figure 3) [43,44]. These effects suggest not just the improvement of response speed, but also two possibilities for new applications of liquid 
crystals: light scattering displays and memory. Firstly, because of the formation of random dispersion of gelators, nematic LC gels was found to be suitable for light scattering displays switching electrooptically between turbid and transparent states [35,38-41]. When the fibrous assembly of a gelator occurs at a temperature higher than the isotropic-anisotropic transition temperature of a liquid crystal component, a randomly dispersed fiber network is formed in the isotropic medium [34]. As no polarizer is needed in light scattering electrooptical displays, the brightness of the displays becomes higher. Due to its simple device structure, light scattering electrooptical switching is expected to be useful for large area display [35]. Secondly, they also found that rewritable bistable nematic materials exhibiting light-scattering and transparent states have been achieved by a combination of thermal and electric stimuli [42]. That is to say, it can be used as a memory. Association of a gelator in a liquidcrystalline phase induces the formation of an oriented self-assembled fiber network, resulting in an oriented liquid-crystalline gel after removal of the electric fields. In this case, the liquid crystal serves as a template [34].

These new initiatives are based on the particular characteristics of amino acids. Amino acids are very functional molecular frames when designing a gelator because they have the advantages of easy chemical modification and polymerization, bringing chirality to the compound, and providing hydrogen-bond interactions. Utilization of non-natural amino acids or peptides might provide clues to help in the development of alternative functional liquid crystals and allow them to be put to practical use.

\section{Liquid Crystals and Doping Agents}

As described above, new applications have been created by introducing amino acids or derivatives into the chemical structures of liquid crystals. Kato and collaborators have succeeded in creating new liquid crystal functionality by making gelators which contain amino acids or derivatives. In contrast we are attempting to find ways to add new function to liquid crystals by dispersing the biomaterials themselves. As a first step, we have focused on DNA because of its stability and structural simplicity. We have prepared liquid crystal samples doped with oligonucleotide DNA (ssDNA or dsDNA) and investigated the effects. We have found two favorable characteristics. Firstly, by measuring the voltage-transmittance $(\mathrm{V}-\mathrm{t})$ response, we have succeeded in determining the characteristics of the frequency modulation (FM) response in twist nematic liquid crystal displays (TN-LCDs) doped with guanine 10-base (G10b; 5'-GGGGGGGGGG-3') at concentrations of 100 and $500 \mu \mathrm{M}$, where 5CB (nematic LC) was used as the host medium. Figure 4 shows the FM response result. Thus, it is possible to drive the LCD device by changing the frequency of the applied voltage without changing the amplitude [45]. Shiraishi and coworkers also reported that nematic LCDs doped with metal nanoparticles, such as Pd, Ag, and Ag-Pd composites, exhibit an FM electro-optical response [46-50]. Applying an electrical field with changing frequency these LCDs doped with metal nanoparticles show a faster switching response than undoped-conventional TN-LCDs [48]. The rapid change in the dielectric anisotropy caused by changing frequency would seem to explain the fast response [48]. We expect that this characteristic would find application as a new control method to improve the response speed of LCDs. Secondly, measurement of the Circular Dichroism (CD) spectra demonstrates that dsDNA produced a twist deformation of the liquid crystal system as determined by a microscopic analysis of the CD data, while ssDNA does not [51]. Furthermore, it should be noted that the 
magnitude of twisting power is different for the A-T and G-C DNA pairs [51]. This twist deformation might originate from the molecular conformation of dsDNA. Due to the cooperative nature of liquid crystal ordering, however, a small amount of chiral dopant in an otherwise achiral mesophase is often enough to select out one domain handedness, making the system chiral overall. The results of the CD spectra suggest that dsDNA may be of use as a chiral dopant that regulates the twist of liquid crystals. These observations are a result of the use of DNA and as such it may be difficult to create variations in such materials because DNA consists of only four kinds of base units, namely, adenine, thymine, cytosine, and guanine. In contrast, peptides are attractive compounds because they can be designed with respect to the various amino acids. Typical commercially available chiral compounds have rather low helical twisting powers, mostly due to shape, size, polarisation, or conformational incompatibility with the LC host [52]. Therefore, a favorable peptide could possess low-molecular-weight, dipole moment, inter- or intra-molecule conformation, or a polymer structure.

Figure 4. Electrooptic characteristics of LC cells. The frequency of the operating voltage is used as a parameter. Open dots indicate the experimental data from LC cell doped with (A) G10b $(100 \mu \mathrm{M})$ or $($ B $) \mathrm{G10b}(500 \mu \mathrm{M})$, and filled dots indicate that from LC cell with pure 5CB, respectively. Adapted with permission from [45]. Copyright 2011 The Japan Society of Applied Physics

(A)

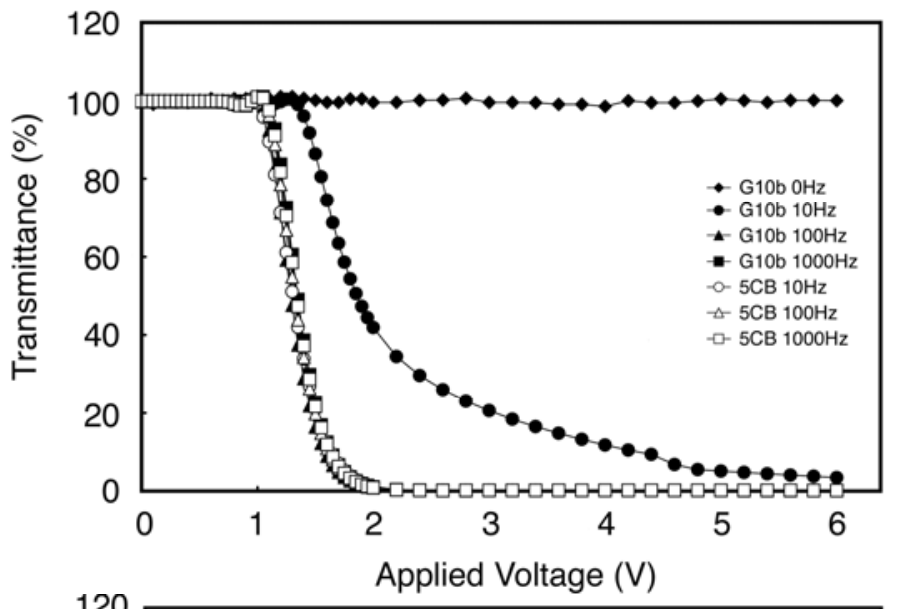

(B)

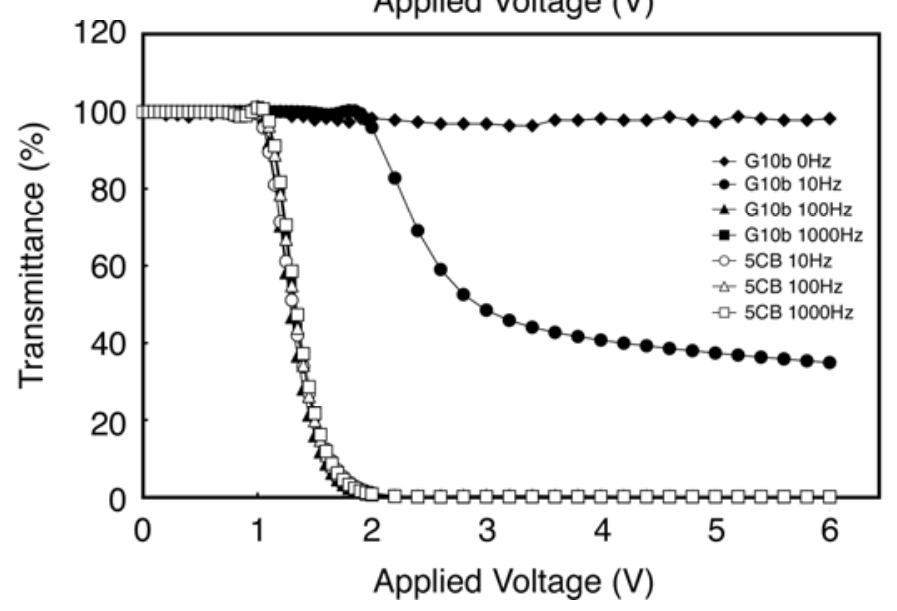




\section{Biological Applications}

During a series of measurements, some interesting results have emerged and these will be discussed in relation to their biological applications. First, we measured the dielectric properties of NLCs doped with ssDNA (A10b, C10b, G10b, and T10b) [53]. The result shows that 5CB doped with oligonucleotide exhibits dielectric relaxation from $10^{1}$ to $10^{2} \mathrm{~Hz}$, as shown in Figure 5.

Figure 5. Dielectric relaxation dependent on the concentration of $\mathrm{C} 10 \mathrm{~b}$. The dielectric permittivity of $5 \mathrm{CB}$ doped with various concentrations of $\mathrm{C} 10 \mathrm{~b}$ was analyzed; orange circles, green squares and blue triangles indicate the experimental data from 5CB doped with $200 \mu \mathrm{M}(0.05 \mathrm{wt} \%), 500 \mu \mathrm{M}(0.14 \mathrm{wt} \%)$ and $1000 \mu \mathrm{M}(0.27 \mathrm{wt} \%) \mathrm{C} 10 \mathrm{~b}$, respectively. The red rhombic dots indicate the data from pure $5 \mathrm{CB}$ as a reference. (A) shows the real part of the dielectric permittivity $\varepsilon$ ' and (B) shows the imaginary part of the dielectric permittivity $\varepsilon$ ". Adapted with permission from [53]. Copyright 2010 The Japan Society of Applied Physics.

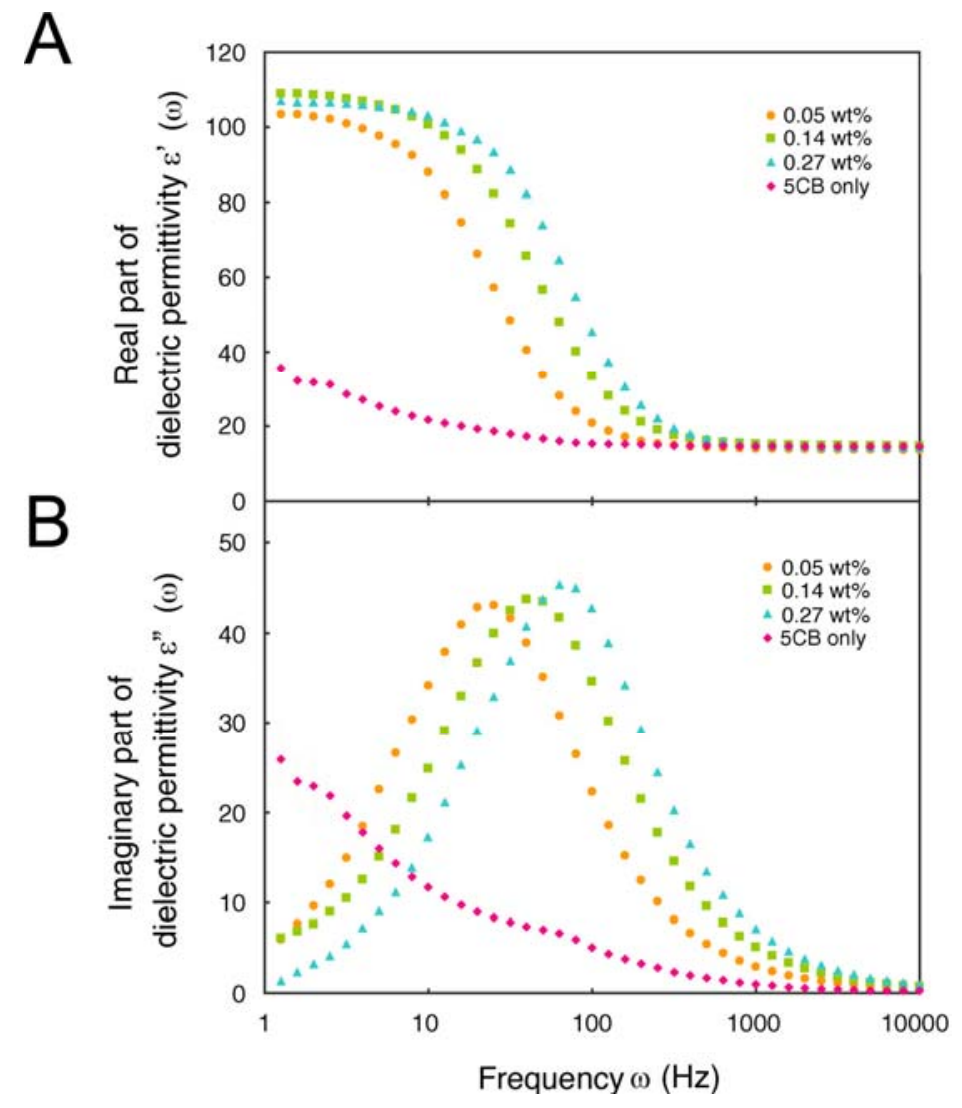

This suggests that the oligonucleotide exists as a polar molecule in the liquid crystal media. Kobayashi et al. reported the same phenomenon using nematic liquid crystals doped with metal nanoparticles, and explained it with their crystal model and by an equivalent circuit approach [54]. We also applied this theory to our experimental results. Consequently, we compared the electric conductivities of the four bases and found that the values for adenine and thymine were distinct from those of cytosine and guanine. This result suggests that the difference in electrical conductivity contributes to the number of hydrogen bonds. This contribution also affects the dielectric permittivity. 
A number of experimental and theoretical studies have been performed to clarify the electrical conducting properties of DNA duplexes [55-86].

Second, by measuring ion density, we examined whether ion density was affected by the identity of the DNA base. Inoue et al. described an analysis method which can judge the polarity of mobile materials in an LC layer from the asymmetric characteristics of a voltage vs. current (I-V) curve, known as ion density measurement [87]. From this curve, we could estimate the ion density of a LC cell. We prepared LC (MLC6884, Merck) samples doped with various oligonucleotides (A10b, G10b, $\mathrm{C} 10 \mathrm{~b}$ and $\mathrm{T} 10 \mathrm{~b}$ ) at different concentrations and fabricated LC cells. As a result, we obtained a linear correlation between various concentrations of oligonucleotides and ion density of LC cells on a graph using a logarithmic scale. Figure 6 shows the correlation characteristics of LC cells doped with G10b.

Figure 6. Concentration characteristics of LC cells doped with G10b. (A) Each line represents the I-V curve of the LC cell doped with G10b at different concentrations; red line: $400 \mu \mathrm{M}$, orange line: $200 \mu \mathrm{M}$ : green line: $100 \mu \mathrm{M}$, and blue line: $50 \mu \mathrm{M}$. (B) Shows the relationship between concentration of G10b and ion density of LC cells, calculated from the peak at positive voltage application. The horizontal and vertical axes of our measurement results are concentration of G10b in LC cells and ion density of LC cells, respectively.

(A)

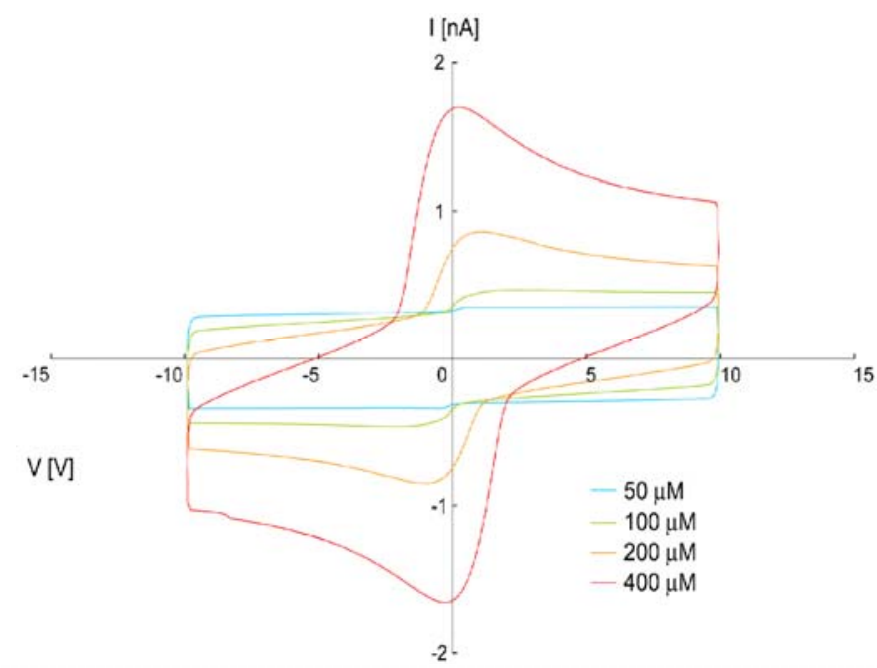

(B)

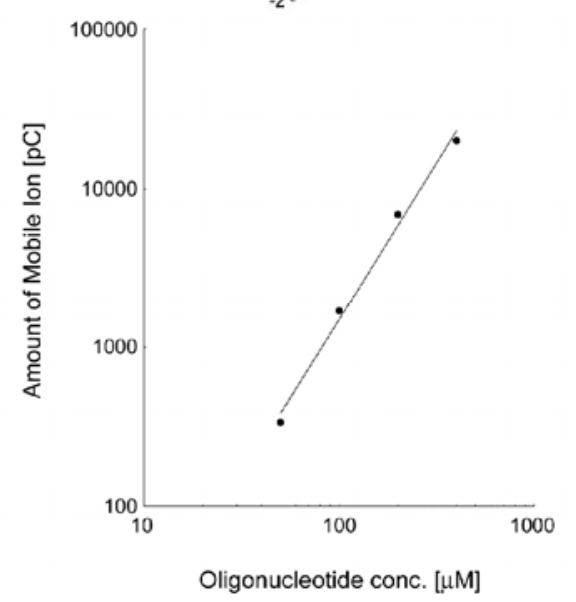

It should be noted that there is a difference between the fitting parameters [88]. This result suggests that ion density is affected by the identity of DNA base. Taking the results together, we found that oligonucleotides show a sequence specific correlation between concentration and the amount of mobile 
ions in LC cells [88]. These studies suggest that dielectric and ion density measurements could open new opportunities for analysis of the electrical properties of biological molecules. It is an important point to note that that the measurement using liquid crystal can completely exclude the effect of water molecules, which always interferes with electrical analysis.

Incidentally, there have been some reports describing early successes for new liquid-crystal material applications with notable biomedical and biological implications. Devices and configurations based on liquid-crystal materials are being developed for spectroscopy, imaging and microscopy, leading to new techniques for optically probing biological systems [89]. Also, a series of investigations have reported biosensors which use the interface of thermotropic liquid crystals as a detection system [90]. One example is that Brake and colleagues reported that the spontaneous assembly of phospholipids at planar interfaces between thermotropic liquid crystals and aqueous phases gives rise to an ordering transition of the liquid crystals [91]. The system based on the ordering transition of LC interfaces is available as optical sensors to monitor for binding events. A series of recent reports has demonstrated that a rich diversity of amphiphilic molecules, such as phospholipids, surfactants, and polymers can assemble at interfaces formed between thermotropic liquid crystals and immiscible aqueous phases [92]. With advancing technology, the preparation of peptide-modified interfaces has received a great deal of attention due to the potential utility of these interfaces for monitoring enzymatic activities, controlling cellular behaviors, and manipulating peptide-protein interactions [93,94]. Lundgren and colleagues developed a liquid crystal pixel array for a high number of signal discrimination [95]. The results described here will be the first step in utilizing liquid crystals as new biotechnological tools. In the near future, moreover, we expect the techniques to be applicable for investigating plasma membranes, liposomes and other domains or structures which show liquid crystallinity within cells.

\section{Conclusions}

In this review, we describe some possibilities of biomaterials applied to the liquid crystal industry. Physical gelation of liquid crystals by an amino acids-based gelator improves the performance of LCDs. DNA could be a chiral dopant and provide the new method of LCD regulation. New functionalities such as scattering displays and memory are added to liquid crystal by gelators. On the other hand, measurements of liquid crystal doped with biomaterials are potentially applicable as new biotechnological tools. These new initiatives make us feel the potential of biomaterials not only for medical and biological application but also for electronic device industrial usage. The research achieving the improvement of photovoltaic and organic field effect transistor device shows a good example of biomaterials' availability. Although we only refer to liquid crystal examples, these biomaterials may have applicability in industrial use if they are considered as an interesting material with the potential to create or refine an industrial product by developing processes that take advantage of their electrical, physical, and structural properties.

\section{Acknowledgments}

We thank S. Fujioka and T. Haruyama for technical help; S. Kobayashi for useful discussions; M. Inoue, Y. Kaneko and TOYO Corporation for technical help with the liquid crystal measurements. 


\section{References}

1. Ulijn, R.V.; Smith, A.M. Designing peptide based nanomaterials. Chem. Soc. Rev. 2008, 37, 664-675.

2. Cavalli, S.; Albericio, F.; Kros, A. Amphiphilic peptides and their cross-disciplinary role as building blocks for nanoscience. Chem. Soc. Rev. 2010, 39, 241-263.

3. Hamley, I.W. Self-assembly of amphiphilic peptides. Soft Matter 2011, 7, 4122-4138.

4. Zhao, X.; Pan, F.; Xu, H.; Yaseen, M.; Shan, H.; Hause, C.A.E.; Zhang, S.; Lu, J.R. Molecular self-assembly and applications of designer peptide amphipholes. Chem. Soc. Rev. 2010, 39, 3480-3498.

5. Versluis, F.; Marsden, H.R.; Kros, A. Power struggles in peptide-amphiphile nanostructures. Chem. Soc. Rev. 2010, 39, 3434-3444.

6. Seeman, N.C. DNA in a material world. Nature 2003, 421, 427-431.

7. Gothelf, K.V.; LaBean, T.H. DNA-programmed assembly of nanostructures. Org. Biomol. Chem. 2005, 3, 4023-4037.

8. Chworos, A.; Severcan, I.; Koyfman, A.Y.; Weinkam, P.; Oroudjev, E.; Hansma, H.G.; Jaeger, L. Building Programmable Jigsaw Puzzles with RNA. Science 2004, 306, 2068-2072.

9. Leontis, N.B.; Lescoute, A.; Westhof, E. The building blocks an motifs of RNA architecture. Curr. Opin. Struct. Biol. 2006, 16, 279-287.

10. Severcan, I.; Geary, C.; Verzemnieks, E.; Chworos, A.; Jaeger, L. Square-Shaped RNA Particles from Different RNA Folds. Nano Lett. 2009, 9, 1270-1277.

11. Gazit, E. Self-assembled peptide nanostructures: The design of molecular building blocks and their technological utilization. Chem. Soc. Rev. 2007, 36, 1263-1269.

12. Reches, M.; Gazit, E. Casting metal nanowires within discrete self-assembled peptide nanotubes. Science 2003, 300, 625-627.

13. Ghadiri, M.R.; Granja, J.R.; Milligan, R.A.; McRee, D.E.; Khazanovich, N. Self-assembling organic nanotubes based on a cyclic peptide architecture. Nature 1993, 366, 324-327.

14. Hartgerink, J.D.; Beniash, E.; Stupp, S.I. Self-assembly and mineralization of peptide-amphiphile nanofibers. Science 2001, 294, 1684-1688.

15. Löwik, D.W.P.M.; Leunissen, E.H.P.; van den Heuvel, M.; Hansen, M.B.; van Hest, J.C.M. Stimulus responsive peptide based materials. Chem. Soc. Rev. 2010, 39, 3394-3412.

16. Scheibel, T.; Parthasarathy, R.; Sawicki, G.; Lin, X.M.; Jaeger, H.; Lindquist, S.L. Conducting nanowires built by controlled self-assembly of amyloid fibers an selective metal deposition. Proc. Natl. Acad. Sci. USA 2003, 100, 4527-4532.

17. Del Mercato, L.L.; Pompa, P.P.; Maruccio, G.; Torre, A.D.; Sabella, S.; Tamburro, A.M.; Cingolani, R.; Rinaldi, R. Charge transport and intrinsic fluorescence in amyloid-like fibrils. Proc. Natl. Acad. Sci. USA 2007, 104, 18019-18024.

18. Kumar, R.; MacDonald, J.M.; Singh, Th.B.; Waddington, L.J.; Holmes, A.B. Hierarchical Self-assembly of semiconductor functionalized peptide $\alpha$-helices and optoelectronic properties. J. Am. Chem. Soc. 2011, 133, 8564-8573.

19. Kawamoto, H. The History of Liquid-Crystal Displays. Proc. IEEE 2002, 90, 460-500.

20. Nishii, M.; Matsuoka, T.; Kamikawa, Y.; Kato, T. Thermotropic liquid-crystalline peptide derivatives: Oligo(glutamic acid)s forming hydrogen-bonded columns. Org. Biomol. Chem. 2005, 3, 875-880. 
21. Kamikawa, Y.; Kato, T. One-dimensional chiral self-assembly of pyrene derivatives based on dendritic oligopeptides. Org. Lett. 2006, 8, 2463-2466.

22. Gao, B.; Li, H.; Xia, D.; Sun, S.; Ba, X. Amphiphilic dendritic peptides: Synthesis and behavior as an organogelator and liquid crystal. Beilstein J. Org. Chem. 2011, 7, 198-203.

23. Hamley, I.W. Liquid crystal phase formation by biopolymers. Soft Matter 2010, 6, 1863-1871.

24. Robinson, C. Liquid-crystalline structures in polypeptide solutions. Tetrahedron 1961, 13, 219-234.

25. Reich, Z.; Wachtel, E.J.; Minsky, A. Liquid-crystalline mesophases of plasmid DNA in bacteria: Regulation of DNA supramolecular organization by supercoiling. Science 1994, 264, 1460-1463.

26. Livolant, F. Ordered phases of DNA in vivo and in vitro. Physica A 1991, 176, 117-137.

27. Livolant, F.; Leforestier, A. Condensed phases of DNA: Structures and phase transitions. Prog. Polym. Sci. 1996, 21, 1115-1164.

28. Rey, A.D. Liquid crystal models of biological materials and processes. Soft Matter 2010, 6, 3402-3429.

29. Ciferri, A. A supermolecular polymerization model for the structurisation of DNA-lipid complexes. Liquid Crystals 2012, 39, 1231-1236.

30. Zidovska, A.; Evans, H.M.; Ewert, K.K.; Quispe, J.; Carragher, B.; Potter, C.S.; Safinya, C.R. Liquid crystalline phases of dendritic lipid-DNA self-assemblies: Lamellar, hexagonal, and DNA bundles. J. Phys. Chem. B 2009, 113, 3694-3703.

31. Safinya, C.R.; Ewert, K.K.; Leal, C. Cationic liposome-nucleic acid complexes: Liquid crystal phases with applications in gene therapy. Liquid Crystals 2011, 38, 1715-1723.

32. Powell, M.F.; Fleitman, J.; Sanders, L.M.; Si, V.C. Peptide liquid crystals: Inverse correlation of kinetic formation and thermodynamic stability in aqueous solution. Pharm. Res. 1994, 11, 1352-1354.

33. Engels, T.; von Rybinski, W. Liquid crystalline surfactant phases in chemical applications. J. Mater. Chem. 1998, 8, 1313-1320.

34. Kato, T.; Mizoshita, N.; Kishimoto, K. Functional liquid-crystalline assemblies: Self-organized soft materials. Angew. Chem. Int. Ed. Engl. 2006, 45, 38-68.

35. Mizoshita, N.; Suzuki, Y.; Kishimoto, K.; Hanabusa, K.; Kato, T. Electrooptical properties of liquid-crystalline physical gels: A new oligo(amino acid) gelator for light scattering display materials. J. Mater. Chem. 2002, 12, 2197-2201.

36. Mizoshita, N.; Hanabusa, K.; Kato, T. Fast and high-contrast electro-optical switching of liquid-crystalline physical gels: Formation of oriented microphase-separated structures. Adv. Funct. Mater. 2003, 13, 313-317.

37. Mizoshita, N.; Hanabusa, K.; Kato, T. Self-Aggregation of an Amino Acid Derivative as a Route to Liquid-Crystalline Physical Gels - Faster Response to Electric Fields. Adv. Mater. 1999, 11, 392-394.

38. Hirai, Y.; Mizoshita, N.; Moriyama, M.; Kato, T. Self-Assembled Fibers Photopolymerized in Nematic Liquid Crystals: Stable Electrooptical Switching in Light-Scattering Mode. Langmuir 2009, 25, 8423-8427.

39. Suzuki, Y.; Mizoshita, N.; Hanabusa, K.; Kato, T. Homeotropically Oriented Nematic Physical Gels for Electrooptical Materials. J. Mater. Chem. 2003, 13, 2870-2874.

40. Mizoshita, N.; Suzuki, Y.; Kishimoto, K.; Kato, T.; Hanabusa, K. Light Scattering Electrooptic Behavior of Liquid-Crystalline Physicail Gels - Effects of Microphase-Separated Morphologies. Mol. Cryst. Liq. Cryst. 2004, 409, 175-181. 
41. Kato, T. Self-Assembly of Phase-Segregated Liquid Crystal Structures. Science 2002, 295, 2414-2418.

42. Mizoshita, N.; Suzuki, Y.; Hanabusa, K.; Kato, T. Bistable Nematic Liquid Crystals with Self-Assembled Fibers. Adv. Mater. 2005, 17, 692-696.

43. Nair, G.G.; Prasad, S.K.; Jayalakshmi, V.; Shanker, G.; Yelamaggad, C.V. Fast Responding Robust Nematic Liquid Crystalline Gels Formed by a Monodisperse Dipeptide: Electro-Opric and Rheological Studies. J. Phys. Chem. B 2009, 113, 6647-6651.

44. Bhargavi, R.; Nair, G.G.; Prasad, S.K.; Prabhu, R.; Yelamaggad, C.V. Anomalously large bend elastic constant and faster electro-optic response in anisotropic gels formed by a dipeptide. J. Appl. Phys. 2011, 109, 083537.

45. Sawada, N.; Iwabata, K.; Ino, K.; Sugai, U.; Seki, Y.; Kakinuma, D.; Furue, H.; Takatoh, K.; Kobayashi, S.; Sakaguchi, K. Frequency Modulation Response of a Liquid Crystal Electrooptic Device Doped with Guanine Oligonucleotides. Jpn. J. Appl. Phys. 2011, 50, 100210.

46. Shiraishi, Y.; Toshima, N.; Maeda, K.; Yoshikawa, H.; Xu, J.; Kobayashi, S. Frequency modulation response of a liquid-crystal electro-optic device doped with nanoparticles. Appl. Phys. Lett. 2002, 81, 2845-2847.

47. Yoshikawa, H.; Maeda, K.; Shiraishi, Y.; Xu, J.; Shiraki, H.; Toshima, N.; Kobayashi, S. Frequency Modulation Response of a Tunable Birefringent Mode Nematic Liquid Crystal Electrooptic Device Fabricated by Doping Nanoparticles of Pd Covered with Liquid-Crystal Molecules. Jpn. J. Appl. Phys. 2002, 41, L1315.

48. Miyama, T.; Thisayukta, J.; Shiraki, H.; Sakai, Y.; Shiraishi, Y.; Toshima, N.; Kobayashi, S. Fast Switching of Frequency Modulation Twisted Nematic Liquid Crystal Display Fabricated by Doping Nanoparticles and Its Mechanism. Jpn. J. Appl. Phys. 2004, 43, 2580-2584.

49. Thisayukta, J.; Shiraki, H.; Sakai, Y.; Masumi, T.; Kundu, S.; Shiraishi, Y.; Toshima, N.; Kobayashi, S. Dielectric Properties of Frequency Modulation Twisted Nematic LCDs Doped with Silver Nanoparticles. Jpn. J. Appl. Phys. 2004, 43, 5430-5434.

50. Shiraki, H.; Kundu, S.; Sakai, Y.; Masumi, T.; Shiraishi, Y.; Toshima, N.; Kobayashi, S. Dielectric Properties of Frequency Modulation Twisted Nematic LCDs Doped with Palladium (Pd) Nanoparticles. Jpn. J. Appl. Phsy. 2004, 43, 5425-5429.

51. Furue, H.; Kakinuma, D.; Toizumi, R.; Fujita, Y.; Iwabata, K.; Sakaguchi, K. Effect of DNA Doping on Liquid Crystal. Mol. Cryst. Liquid Cryst. 2011, 540, 213-218.

52. Eelkema, R.; Feringa, B.L. Amplification of chirality in liquid crystals. Org. Biomol. Chem. 2006, 4, 3729-3745.

53. Iwabata, K.; Nakabayashi, T.; Uchiyama, Y.; Inoue, M.; Taki, S.; Ando, K.; Sakai, H.; Abe, M.; Itagaki, M.; Furue, H.; Kobayashi, S.; Sakaguchi, K. Dielectric Relaxation Analysis of Single-Stranded DNA in Liquid Crystals. Jpn. J. Appl. Phsy. 2010, 49, 87002.

54. Kobayashi, S.; Miyama, T.; Nishida, N.; Sakai, Y.; Shiraki, H.; Shiraishi, Y.; Toshima, N. Dielectric Spectroscopy of Metal Nanoparticle Doped Liquid Crystal Displays Exhibiting Frequency Modulation Response. J. Disp. Technol. 2006, 2, 121-129.

55. Meggers, E.; Michel-Beyerle, M.E.; Giese, B. Sequence Dependent Long Range Hole Transport in DNA. J. Am. Chem. Soc. 1998, 120, 12950-12955.

56. Giese, B. Long-Distance Charge Transport in DNA: The Hopping Mechanism. Acc. Chem. Res. 2000, 33, 631-636. 
57. Giese, B. Electron transfer in DNA. Curr. Opin. Chem. Biol. 2002, 6, 612-618.

58. Barnett, R.N.; Cleveland, C.L.; Landman, U.; Boone, E.; Kanvah, S.; Schuster, G.B. Effect of Base Sequence and Hydration on the Electronic and Hole Transport Properties of Duplex DNA: Theory and Experiment. J. Phys. Chem. A 2003, 107, 3525-3537.

59. Xu, B.; Zhang, P.; Li, X.; Tao, N. Direct Conductance Measurement of Single DNA Molecules in Aqueous Solution. Nano Lett. 2004, 4, 1105-1108.

60. Xu, M.S.; Endres, R.G.; Tsukamoto, S.; Kitamura, M.; Ishida, S.; Arakawa, Y. Conformation and Local Environment Dependent Conductance of DNA Molecules. Small 2005, 1, 1168-1172.

61. Sugiyama H.; Saito, I. Theoretical Studies of GG-Specific Photocleavage of DNA via Electron Transfer: Significant Lowering of Ionization Potential and 5'-Localization of HOMO of Stacked GG Bases in B-Form DNA. J. Am. Chem. Soc. 1996, 118, 7063-7068.

62. Tada, T.; Kondo, M.; Yoshizawa, K. You have full text access to this contentTheoretical Measurements of Conductance in an (AT) 12 DNA Molecule. ChemPhysChem 2003, 4, 1256-1260.

63. Starikov, E.B.; Tanaka, S.; Kurita, N.; Sengoku, Y.; Natsume, T.; Wenzel, W. Investigation of a Kubo-formula-based approach to estimate DNA conductance in an atomistic model. Eur. Phys. J. E 2005, 18, 437-445.

64. Starikov, E.B.; Fujita, T.; Watanabe, H.; Sengoku, Y.; Tanaka, S.; Wenzel, W. Effects of molecular motion on charge transfer/transport through DNA duplexes with and without base pair mismatch. Mol. Simulation 2006, 32, 759-764.

65. Starikov, E.B.; Quintilla, A.; Nganou, C.; Lee, K.H.; Cuniberti, G.; Wenzel, W. Single-molecule DNA conductance in water solutions: Role of DNA low-frequency dynamics. Chem. Phys. Lett. 2009, 467, 369-374.

66. Lewis, J.P.; Cheatham, T.E.; Starikov, E.B.; Wang, H.; Sankey, O.F. Dynamically Amorphous Character of Electronic States in Poly(dA)-Poly(dT) DNA. J. Phys. Chem. B 2003, 107, 2581-2587.

67. Troisi A.; Orlandi, G. Hole Migration in DNA: A Theoretical Analysis of the Role of Structural Fluctuations. J. Phys. Chem. B 2002, 106, 2093-2101.

68. Voityuk, A.A.; Siriwong, K.; Rösch, N. You have full text access to this contentEnvironmental Fluctuations Facilitate Electron-Hole Transfer from Guanine to Adenine in DNA $\pi$ Stacks. Angew. Chem. Int. Ed. Engl. 2004, 43, 624-627.

69. Voityuk, A.A. Assessment of semiempirical methods for the computation of charge transfer in DNA $\pi$-stacks. Chem. Phys. Lett. 2006, 427, 177-180.

70. Van Zalinge, H.; Schiffrin, D.J.; Bates, A.D.; Starikov, E.B.; Wenzel, W.; Nichols, R.J. Variable-Temperature Measurements of the Single-Molecule Conductance of Double-Stranded DNA. Angew. Chem. Int. Ed. Engl. 2006, 45, 5499-5502.

71. Zalinge, H.V.; Schiffrin, D.J.; Bates, A.D.; Haiss, W.; Ulstrup, J.; Nichols, R.J. Single-Molecule Conductance Measurements of Single- and Double-Stranded DNA Oligonucleotides. ChemPhysChem 2006, 7, 94-98.

72. Sadowska-Aleksiejew, A.; Rak, J.; Voityuk, A.A. Effects of intra base-pairs flexibility on hole transfer coupling in DNA. Chem. Phys. Lett. 2006, 429, 546-550.

73. Kelley, S.O.; Boon, E.M.; Barton, J.K.; Jackson, N.M.; Hill, M.G. Single-base mismatch detection based on charge transduction through DNA. Nucleic Acids Res. 1999, 27, 4830-4837. 
74. Okada, A.; Yokojima, S.; Kurita, N.; Sengoku, Y.; Tanaka, S. Charge transfer in duplex DNA containing mismatch. J. Mol. Struct. THEOCHEM 2003, 630, 283-290.

75. Asai, Y. Theory of Electric Conductance of DNA Molecule. J. Phys. Chem. B 2003, 107, 8716.

76. Barnett, R.N.; Cleveland, C.L.; Joy, A.; Landman, U.; Schuster, G.B. Charge Migration in DNA: Ion-Gated Transport. Science 2001, 294, 567-571.

77. Kubar, T.; Woiczikowski, P.B.; Cuniberti, G.; Elstner, M. Efficient Calculation of Charge-Transfer Matrix Elements for Hole Transfer in DNA. J. Phys. Chem. B 2008, 112, 7937-7947.

78. Kubar, T.; Elstner, M. What Governs the Charge Transfer in DNA? The Role of DNA Conformation and Environment. J. Phys. Chem. B 2008, 112, 8788-8798.

79. Senthilkumar, K.; Grozema, F.C.; Guerra, C.F.; Bickelhaupt, F.M.; Lewis, F.D.; Berlin, Y.A.; Ratner, M.A.; Siebbeles, L.D.A. Absolute Rates of Hole Transfer in DNA. J. Am. Chem. Soc. 2005, 127, 14894-14903.

80. Roca-Sanjuan, D.; Merchan, M.; Serrano-Andres, L. Mechanistic insights into the $\mathrm{H}+\mathrm{O} 2 \rightarrow \mathrm{OH}+\mathrm{O}$ reaction from quasi-classical trajectory studies on a new ab initio potential energy surface. Chem. Phys. 2008, 349, 188-187.

81. Roche, S. Sequence Dependent DNA-Mediated Conduction. Phys. Rev. Lett. 2003, 91, 108101-108104.

82. Guo, A.M. Long-range correlation and charge transfer efficiency in substitutional sequences of DNA molecules. Phys. Rev. E 2007, 75, 061915-061922.

83. Tsukamoto, T.; Ishikawa, Y.; Vilkas, M.J.; Natsume, T.; Dedachi, K.; Kurita, N. Density-functional theoretical study on hydrated DNA duplex: Effect of hydrating water molecules on HOMO distribution in DNA. Chem. Phys. Lett. 2006, 429, 563-569.

84. Tsukamoto, T.; Ishikawa, Y.; Natsume, T.; Dedachi, K.; Kurita, N. A combined molecular dynamics/density-functional theoretical study on the structure and electronic properties of hydrating water molecules in the minor groove of decameric DNA duplex. Chem. Phys. Lett. 2007, 441, 136-142.

85. Tsukamoto, T.; Wakabayashi, H.; Sengoku, Y.; Kurita, N. Charge conducting properties of hydrated DNA duplex between Au electrodes obtained by molecular simulations and Green's function theory. Int. J. Quantum Chem. 2009, 109, 2058-2067.

86. Yanov, I.; Palacios, J.J.; Hill, G. Simple STM Tip Functionalization for Rapid DNA Sequencing: An Ab Initio Green's Function Study. J. Phys. Chem. A 2008, 112, 2069-2073.

87. Inoue, M.; Miyake, T.; Akimoto, M.; Kobayashi, S.; Takatoh, K. Changes Caused to Asymmetric I-V Characteristics of LC Cells Having a Single-Sided Alignment Layer Structure by Doping 4-Dimethyl-aminopyridine (4-DMAP) into an LC Layer. Mol. Cryst. Liq. Cryst. 2009, 510, 312-322.

88. Iwabata, K.; Seki, Y.; Toizumi, R.; Shimada, Y.; Inoue, M.; Furue, H.; Sakaguchi, K. Ion Density Analysis of Single-Stranded DNA in Liquid Crystal. Jpn. J. Appl. Phys. Submitted.

89. Woltman, S.J.; Jay, G.D.; Crawford, G.P. Liquid-crystal Materials Find a New Order in Biomedical Applications. Nat. Mater. 2007, 12, 929-938.

90. Lowe, A.M.; Abbott, N.L. Liquid Crystalline Materials for Biological Applications. Chem. Mater. 2012, 24, 746-758.

91. Brake, J.M.; Daschner, M.K.; Luk, Y.Y.; Abbott, N.L. Biomolecular Interactions at PhospholipidDecorated Surfaces of Liquid Crystals. Science 2003, 302, 2094-2097. 
92. Kinsinger, M.I; Lynn, D.M.; Abbott, N.L. Nematic ordering drives the phase separation of mixed monolayers containing phospholipids modified with poly(ethylene glycol) at aqueous-Liquid crystal interfaces. Soft Matter 2010, 6, 4095-4104.

93. Park, J.S.; Abbott, N.L. Ordering Transitions in Thermotropic Liquid Crystals Induced by the Interfacial Assembly and Enzymatic Processing of Oligopeptide Amphiphiles. Adv. Mater. 2008, 20, 1185-1190.

94. Park, J.S.; Teren, S.; Tepp, W.H.; Beebe, D.J.; Johnson, E.A.; Abbott, N.L. Formation of Oligopeptide-Based Polymeric Membranes at Interfaces between Aqueous Phases and Thermotropic Liquid Crystals. Chem. Mater. 2006, 18, 6147-6151.

95. Lundgren, J.S.; Watkins, A.N.; Racz, D.; Ligler, F.S. A liquid crystal pixel array for signal discrimination in array biosensors. Biosens. Bioelectron. 2000, 15, 417-421.

(C) 2013 by the authors; licensee MDPI, Basel, Switzerland. This article is an open access article distributed under the terms and conditions of the Creative Commons Attribution license (http://creativecommons.org/licenses/by/3.0/). 